\title{
DE HUSSERL A SARTRE: UMA PROPOSTA ONTOFENOMENOLÓGICA
}

FROM HUSSERL TO SARTRE: A PROPOSAL ONTOPHENOMENOLOGICAL

Neide Coelho Boëchat*

\section{RESUMO}

Este trabalho trata dos princípios fundamentais da fenomenologia de Edmund Husserl e de seu reflexo no pensamento ontofenomenológico de Jean-Paul Sartre. Pretende-se aqui acentuar o fato de que este último ultrapassa o terreno da singularidade humana, própria da pesquisa fenomenológica husserliana, para o âmbito da história, investigando o homem em sua individualidade, sem perder de vista seu movimento histórico-político que o coloca no âmbito do universal e, consequentemente, na possibilidade de uma construção moral.

PALAVRAS-CHAVES: Fenomenologia. Consciência. Liberdade. Escassez. Moral.

\begin{abstract}
This work deals with the fundamental principles of the phenomenology of Edmund Husserl and his reflection in ontofenomenological thought of Jean-Paul Sartre. It is intended here to emphasize the fact that the latter goes beyond the realm of human uniqueness, own the phenomenological research husserliana, into the realm of history, investigating the man as an individual, without losing sight of its historical and political movement that puts within the universal and therefore the possibility of a morale construction.
\end{abstract}

KEYWORDS: Phenomenology. Consciousness. Freedom. Scarcity. Morale.

\footnotetext{
* Professora no Centro Universitário Assunção - UNIFAI. E-mail: neideboechat@ hotmail.com
} 


\title{
Introdução
}

A fenomenologia despontou no fim do século XIX, com Edmund Husserl (1859-1938), um matemático, portador de uma racionalidade voltada para a exatidão e para o rigor da metodologia científica, mas que se interessou pela filosofia, ao conhecer o pensamento de Franz Brentano (1838-1917).

Brentano foi um grande pesquisador da filosofia aristotélica e que mais tarde voltou-se para a psicologia, tentando introduzir em suas pesquisas o elemento empírico. Ele almejava a construção de uma filosofia científica e, com esse objetivo, desenvolveu seus trabalhos nas esferas da psicologia, apoiando-se no método descritivo. Em 1874, publica sua conhecida obra: Psicologia do ponto de vista empírico, na qual ressalta o caráter intencional da consciência, deixando, dessa forma, uma abertura para a fenomenologia.

Husserl interessou-se pela psicologia descritiva de Brentano e aplicou seus conhecimentos às pesquisas que vinha desenvolvendo acerca da matemática. $\mathrm{O}$ resultado dessa aproximação se concretizou na publicação da obra Filosofia da aritmética, em 1891.

Mais tarde, em 1900, em suas Investigações lógicas, Husserl dá início à sua luta contra o psicologismo. Segundo Stegmüller (1997, p. 58-59), o ponto de partida de sua refutação ao psicologismo é a ideia de uma lógica pura como disciplina teórica.

\begin{abstract}
A corrente caracterizada por ele como psicologista afirma que a lógica é uma técnica do pensamento correto e que as leis lógicas são leis reais de nosso pensar, obtidas através de análises empírico-psicológicas, sendo verdadeiro o que corresponde a tais leis do pensar [...]. O psicologismo afirma que o pensar e o conhecer são eventos psíquicos e que, por isso a lógica trata de leis psicológicas.
\end{abstract}

Husserl destaca o absurdo dessas teorias, pois considerando que psicologia é uma ciência natural que se desenvolve sob um método explicativo, apoiado na causalidade, tais proposições acabam por desembocar, ao mesmo tempo, no ceticismo, e no relativismo como consequência. Mais objetivamente, o que estava em questão era a relação entre a objetividade do objeto conhecido e o pensamento elaborado acerca desse conhecimento. O que interessava a Husserl era a constituição desse pensamento, ou seja, os modos de consciência que conduzem ao pensamento.

Entretanto, apesar de toda a crítica desenvolvida ao psicologismo brentaniano, o conceito de intencionalidade da consciência ainda despertava seu interesse. É pois, com esse objetivo que ele aprofunda suas investigações acerca das estruturas dos atos intencionais. 
Enquanto crítico do psicologismo em suas Investigações lógicas, encontramos em Husserl um filósofo realista. Contudo, alguns anos mais tarde, uma virada teórica se impõe em seu pensamento, e suas ideias acerca da relação do homem com o mundo passa por uma nova apreensão. Vejamos algumas de suas afirmações:

[...] nenhum ser real, nenhum ser que se exiba e ateste por aparições à consciência, é necessariamente, para o ser da própria consciência (no sentido mais amplo do vivido).O ser imanente é, portanto, indubitavelmente ser absoluto no sentido de que ele, por princípio, nulla "re" indigest ad existendum" ${ }^{1}$. Por outro lado, o mundo da "res" transcendente é inteiramente dependente da consciência, não da consciência pensada logicamente, mas da consciência atual. (HUSSERL, 2006, § 49).

Sem dúvida, o resultado dessas novas investigações surpreendeu até mesmo seus antigos discípulos que o acompanharam em seu período realista. O mestre assumia então uma postura inteiramente idealista ao expor suas novas premissas, em sua obra de 1913: Ideias para uma fenomenologia pura.

\section{A orientação natural e a orientação fenomenológica}

Husserl pretendia fazer da filosofia uma ciência rigorosa e bem fundamentada. Contudo, como crítico do positivismo, sua proposta em tudo se distanciava das ciências naturais e positivas cujo rigor reduzia a simples fatos o que pertencia à esfera do humano.

Dessa forma, a fenomenologia se manifesta como a possibilidade de escapar, ao mesmo tempo, do positivismo e do psicologismo subjetivista e manter-se como uma ciência dos fenômenos, ou seja, uma ciência descritiva que se afirmaria - diferentemente das ciências naturais - pelas esferas da intuição.

Essa nova forma de fazer filosofia adota como ponto de partida uma dupla orientação: a orientação natural e a orientação fenomenológica. Husserl entende por orientação natural a forma espontânea e imediata com que o homem se coloca no "mundo da vida" entre os demais seres animais, humanos e não humanos que o cercam, entre os objetos que lhes servirão como utensílios, sem que seja sequer necessário que estes se encontrem em seu campo perceptivo, pois na medida em que ele "sabe" que fazem parte do seu meio circundante e que está cônscio deste saber, tal saber se transforma em uma intuição clara (HUSSERL, 2006, § 27). Isto não significa, entretanto, que este "mundo da vida" não seja

\footnotetext{
1 "Não carece de coisa alguma para existir" (Nota do tradutor Marcio Suzuki)
} 
passível de dúvida. Ao contrário, podemos duvidar dos dados do mundo natural e essa dúvida pode, inclusive, tornar mais apurada a nossa percepção imediata. O que não se altera é a tese intrínseca à atitude natural. É exatamente por isso que Husserl pode considerar as investigações científicas como provenientes desse tipo de atitude. De fato, toda ciência começa com uma hipótese e uma tese que se origina do mundo. Logo, não só o senso comum, mas também os cientistas partem de uma orientação natural.

Todas as chamadas ciências da natureza, tanto em sentido mais estrito, como as ciências da natureza material, quanto também em sentido mais amplo, como as ciências dos seres animais com sua natureza psicofísica, portanto também a fisiologia, a psicologia, etc. são ciências do mundo, ou seja, ciências da orientação natural (HUSSERL, 2006, § 1).

Contudo, numa referência à dúvida metódica de Descartes $^{2}$, Husserl coloca a possibilidade de nos colocarmos de uma outra forma diante do mundo, ou seja, de suspender esta atitude natural em função de uma orientação fenomenológica e empreender uma modificação na tese anterior. Todavia, não se trata de uma conversão de tese em antítese, da posição em negação. Não é o caso de abandonar a tese anterior, aliás, não modificamos em nada a nossa convicção. Do que se trata é de tirar de circuito ou de colocarmos entre parênteses a tese já conhecida. Ela não é eliminada, ao contrário, continua presente mas, ao lado dela, desponta um determinado modo específico de consciência que modifica o valor da tese original. (HUSSERL, 2006, § 31), ou seja, a atenção se volta, não mais para as coisas, ou objetos do mundo, mas para os fenômenos. Esse movimento é o que Husserl reconhece como redução fenomenológica, isto é, realiza-se uma epoché, ou melhor, suspendemos o juízo referente à tese natural do mundo. Estamos, portanto, diante de dois tipos de objetos cujos surgimentos estão vinculados aos modos pelos quais a consciência se coloca no mundo. $\mathrm{Na}$ orientação natural, ela se coloca, espontaneamente, diante do objeto "puro e "simples", com suas determinações naturais. Na orientação fenomenológica, os objetos não são apreendidos pela consciência como "puro" e "simples", mas como fenômenos da existência, ou seja, como algo que nos aparece e ao qual damos um significado. Pela fenomenologia, a realidade da natureza desaparece, mas retém seu significado; ou seja, retém o sentido de tudo aquilo com o qual estamos vinculados.

\footnotetext{
2 - Husserl (2006, § 31) esclarece que em seu ensaio de dúvida universal Descartes procurou empreender um fim inteiramente outro, diverso do seu. A referência a este ensaio, diz o filósofo, "nos serve apenas como expediente metódico.
} 


\section{A intencionalidade da consciência}

Husserl já havia iniciado sua investigação acerca da consciência com Brentano. Entretanto, segundo ele, Brentano não considerou a origem da função objetivante da consciência, enquanto consciência de algo e, de fato, ser consciência de algo diz respeito ao ser mesmo da consciência. Mas o que significa ser consciência de alguma coisa?

Significa que a consciência está sempre voltada para um ser objetivado por ela; um ser do qual ela é consciência. É exatamente isso que Husserl quer dizer quando afirma que a consciência humana é sempre intencional. Nas Meditações cartesianas, ele afirma:

\footnotetext{
A palavra intencionalidade não significa outra coisa a não ser esta particularidade fundamental e geral que a consciência tem, de ser consciência de qualquer coisa, de levar, na qualidade de cogito, um cogitatum em si mesma. (HUSSERL, 1997, §14)
}

Esse conceito-chave do pensamento de Husserl precisa ser esclarecido com cuidado, pois ao afirmá-lo, ele afirma também o aspecto transcendente da consciência, ou seja, ela está sempre em movimento, sempre voltada para fora de si mesma, isto é, para um fenômeno. A questão é que, quando um fenômeno me aparece, eu o percebo a partir de uma certa perspectiva, o que significa que ao percebê-lo, ele é apreendido pela minha subjetividade e dou a ele um determinado significado. Além disso, tenho também clareza que esse fenômeno que percebo está fora de mim e não em mim. Nada há no interior de uma consciência; ela é sempre vazia, não tem conteúdo. Não podemos afirmar que tal coisa está na minha consciência, pois ela não é uma caixa, ou um pacote, melhor dizendo, ela não tem materialidade. Estamos aqui diante de dois temas fundamentais na fenomenologia de Husserl: a subjetividade e a transcendência.

Resumindo, podemos afirmar que a consciência é dotada de transcendência e portadora de uma subjetividade. Pela transcendência, ela está sempre voltada para as coisas do mundo que, sejam elas quais forem - objetos, seres naturais, artificiais vivos ou inanimados -, não têm, em si mesmas significado algum. No momento de encontro da consciência com a coisa, imediatamente acontece um ato noético: a percepção. A percepção é a noese, isto é, o ato pelo qual ela se coloca diante da coisa. Por outro lado, pela subjetividade, ela significa todas essas coisas, e tais coisas significadas são o que Husserl identifica como noema, isto é, um correlato do objeto intencional percebido pela consciência. 
A importância dessa noção elaborada por Husserl está no fato de que é, exatamente através dela, que o filósofo pôde afirmar que toda consciência é sempre consciência de alguma coisa.

\section{Ontologia e fenomenologia}

Ao fundamentar sua hermenêutica na fenomenologia, Ricoeur o faz através da ontologia da compreensão. E, de fato, tanto Heidegger, por ele citado, como também Sartre e os demais discípulos de Husserl que acabaram por perseguir a filosofia da existência, se desvencilharam da dualidade sujeito-objeto ao investigar a questão do conhecimento, tratando desta problemática como um modo de ser, ou como afirma Ricoeur:

Não se entra pouco a pouco nesta ontologia da compreensão [...] transportamo-nos a ela através de uma súbita inversão da problemática. A questão: em que condição um sujeito que conhece pode compreender um texto, ou a história? é substituída pela questão: o que é um ser cujo ser consiste em compreender? (RICOEUR, 1988, p. 8).

A essa questão Heidegger responde, em Ser e tempo, da seguinte forma: "esse ser se chama sentido ${ }^{3}$. 'Sentido do ser' e 'verdade do ser' dizem a mesma coisa" (HEIDEGGER, 1973, p. 259).

Contudo, Ricoeur argumenta que essa ontologia da compreensão nos exige "compreender bem o sentido da revolução de pensamento que ela propõe", o que significaria, segundo ele, operar uma inversão que vai das Investigações lógicas de Husserl a Ser e Tempo de Heidegger e "considerar em toda a sua radicalidade a inversão da própria questão" (RICOEUR, 1988, p.9). Na verdade, o problema de Ricoeur não se refere à ontologia da compreensão em si mesma, mas sim à "possibilidade de fazer uma ontologia direta, imediatamente subtraída a toda exigência metodológica" (RICOEUR, 1988, p. 8).

Todavia, o que não podemos perder de vista e que já foi aqui apontado, é o fato de que o pensamento de Husserl a partir de 1903 já coloca o homem no "mundo da vida"; antes, portanto, da epoché fenomenológica. Sem dúvida, Husserl deixou para seus discípulos um espaço para se pensar a possibilidade de uma ontologia da compreensão.

Sartre reconhece em L'être et le néant o movimento traçado no decorrer do século XIX ao século XX, em função de um esforço por parte dos filósofos em abandonar o postulado

\footnotetext{
${ }^{3}$ Cf. ainda, em Ser e tempo, p. 151.
} 
sujeito-objeto, estabelecendo "no próprio âmago das consciências um nexo fundamental e transcendente em relação ao outro" (SARTRE, 2001, p.271) e, considerando a fenomenologia de Husserl, ele afirma:

Para Husserl, o mundo, tal como se revela à consciência, é intermonadário. O outro não está presente somente como tal aparição concreta e empírica, mas como condição permanente de sua unidade e sua riqueza [...]; em suma, como a verdadeira garantia de sua subjetividade. (SARTRE, 2001, p. 303).

Não há dúvida de que Husserl pretendia fazer de sua fenomenologia uma ciência fundamental e rigorosa, uma filosofia primeira. Nessa medida, o filósofo se empenhou em uma busca de princípios puros, radicais e necessários que revelassem o sentido ou o significado essencial das coisas e do mundo da vida.

Com esse propósito, a pergunta que guiava suas investigações não poderia ser outra que não uma interrogação sobre o ser. A fenomenologia torna-se assim uma ontologia.

\section{$4 O$ pensamento onto-fenomenológico no existencialismo de Jean-Paul Sartre}

$\mathrm{O}$ existencialismo foi uma corrente filosófica que despontou no século XX, entre as duas grandes guerras mundiais. Um momento de descrença, de desesperança e de desamparo que ameaçava a segurança dos povos europeus.

Diante desse quadro, muitos pensadores se manifestaram, tentando compreender e manifestar seu pensamento.

Jean-Paul Sartre foi um desses filósofos que atuou naquele momento, escrevendo em um jornal por ele fundado (Les Temps Modernes), escrevendo peças de teatro que refletiam as problemáticas do momento e vários escritos filosóficos que hoje compõem uma vasta obra ao alcance de todos que se interessam por seu pensamento.

Sartre deu início a seus estudos pela área da psicologia, pesquisando alguns temas pedido por seus professores. Mais tarde, empenhou-se na construção de sua primeira grande obra: L'être et le néant, que foi seguida pelos dois volumes da Critique de la raison dialectique, e várias outras obras, compondo, enfim, uma grande produção filosófica.

Em L'être et le néant, ainda vinculado à área da psicologia, ele se empenha em investigar a subjetividade humana. Para isso, foi para a Alemanha estudar fenomenologia com Husserl e, sem dúvida, assimilou muitas de suas propostas, mas também refutou várias de suas proposições. 
Entretanto, diferentemente dos demais, Sartre demonstrou desde o início de seus escritos um grande interesse pela questão moral. Podemos observar que todos os conceitos ou noções por ele desenvolvidos têm a moral como horizonte a ser alcançado.

Ao voltar-se para as questões ligadas à subjetividade, Sartre partiu da noção de consciência proposta por Husserl e assimilou quase todos os princípios por ele colocados, mas divergia em um ponto fundamental, isto é, ao afirmar a consciência como vazia de conteúdo, Husserl deixou em seu interior o ego transcendental. Sartre foi bem mais rigoroso que seu mestre e esvaziou completamente a consciência.

\begin{abstract}
Seguimos Husserl em cada uma de suas admiráveis descrições, em que ele mostra a consciência transcendental constituindo o mundo e aprisionando-se na consciência empírica: estamos persuadidos tal como ele que o nosso eu psíquico e psicofísico é um objeto transcendente que deve ficar ao alcance da epoché . Mas fazemo-nos a seguinte pergunta: não é suficiente este eu psíquico e psicofísico? Será preciso duplicá-lo por um eu transcendental? [...] O eu transcendental é a morte da consciência. [...] A consciência tornou-se pesada, ela perdeu esse caráter que fazia dela um absoluto à força de inexistência. (SARTRE, 1994, p. 48-49).
\end{abstract}

Ao negar essa proposta de Husserl, Sartre tira do homem a certeza de poder conhecer-se a si mesmo. Para ele, é impossível que possamos nos conhecer no momento mesmo em que agimos. Quando realizamos a epoché para refletirmos sobre uma situação passada que vivemos, isto é, quando pensamos sobre nossa atitude naquela situação, o eu que nos aparece não é o mais mesmo eu que agiu naquela situação. Por isso, diz Sartre (2001, p. 190): “Conhecer-se é fazer-se outro".

Contudo, o filósofo assimilou a noção de intencionalidade da consciência, tal como Husserl a propôs. Para ele, de fato, a consciência é intencional, vazia, translúcida, está sempre voltada para o mundo de forma imediata e espontânea e é, sobretudo sempre significante.

As características de imediaticidade, de espontaneidade e seu caráter significante fazem do homem um ser responsável por todos os seus atos, pois se a consciência é sempre intencional, se não há nenhum de nossos atos que não esteja livre de intenção, somos, certamente, responsáveis por todos eles. Por outro lado, se as coisas do mundo não têm significado algum e se somos nós, portadores de uma consciência significante, que damos significado a tudo que nos cerca, esse mundo em que vivemos é um mundo criado por nós e, sendo assim, todos os seus obstáculos são resultado dos significados a ele conferidos. Eis um exemplo do próprio filósofo que pode esclarecer melhor tal questão. 
Eis-me aos pés de um rochedo que me aparece como "não escalável". [...] Para o simples viajante que atravessa a estrada e que o projeto é pura ordenação estética da paisagem, o rochedo não se mostra nem como escalável, nem como não-escalável: manifesta-se apenas como belo ou feio (SARTRE, 2000, p.533).

O rochedo em si mesmo é apenas um elemento da natureza, não tem significado algum, mas poderá ser significado como uma ótima oportunidade, continua Sartre mais adiante, "para um alpinista atlético que esteja procurando um rochedo para escalar”. O que ele pretende deixar claro é que o mundo significado por nós pode nos aparecer como favorável ou não dependendo das nossas finalidades. Somos, dessa forma, responsáveis por tudo o que nos acontece, e muito do que nos acontece é contingente. Mas, afirma ele, somos seres contingentes, assim como somos livres. A contingência é necessária, assim como é necessária a liberdade. A ação livre é um poder incondicionado em qualquer circunstância. Logo, diante de cada contingência somos livres para decidir o que fazer.

A liberdade é o tema mais presente no pensamento desse autor. Segundo ele, o homem é ontologicamente livre, logo, não pode deixar de sê-lo; ele está condenado à liberdade, afirmava o filósofo em sua famosa conferência $O$ existencialismo é um humanismo (SARTRE, 1973, p. 15). A liberdade, portanto, aparece em seu pensamento como absolutamente necessária.

Por outro lado, não há uma essência de liberdade, a liberdade é, ela mesma, "o fundamento de todas as essências, posto que o homem desvela as essências intramundanas, ao transcender o mundo rumo as suas possibilidades próprias" (SARTRE, 2001, p. 506). Isso significa que a liberdade é apreendida através dos fatos, logo, ela é contingente; mas é também necessária, na medida em que não posso deixar de experimentá-la; é, portanto, uma necessidade de fato. Dizer que a liberdade é fundamento de todas as essências é conceber uma realidade humana que decide sobre seus próprios fins e escolhe os meios pelos quais pretende alcançá-los. Sejam quais forem os meus meios e os meus fins, eles serão sempre os meios e os fins que escolhi para mim. Ao mesmo tempo, dizer que a liberdade é uma necessidade de fato é dizer também que o homem escolhe a si mesmo, escolhendo seus próprios valores, pois como afirmava o filósofo, "não há valores inscritos em um céu inteligível” (SARTRE, 1978, p.15) e assim, escolhendo-se, o homem escolhe o mundo; o que ele não pode é deixar de escolher, pois não escolher já é, em si mesmo, uma escolha.

O resultado de todo esse processo é o que Sartre caracteriza como situação e, por isso, ele afirma que a nossa liberdade é uma liberdade "em situação". Ele afirma que: 
[...] qualquer que seja a situação em que se encontre, com seu coeficiente de adversidade próprio, ainda que insuportável, o para- $\mathrm{si}^{4}$ deve assumi-la com a consciência orgulhosa de ser o seu autor, pois os piores inconvenientes ou as piores ameaças que prometem atingir a minha pessoa só adquirem sentido pelo meu projeto; e elas aparecem sobre o fundo de comprometimento que eu sou (SARTRE, 2001, p. 598).

A situação é, portanto, o obstáculo necessário que devemos transpor para alcançar um fim; sem a situação, a liberdade não poderia ser exercida. Não se trata, portanto, de uma liberdade abstrata, ela é tratada na concretude de uma realidade humana em busca de seu projeto e se dá, portanto, no âmbito de um “fazer" humano.

Vimos até aqui a pesquisa sartriana voltada para o aspecto singular da existência. Entretanto, não podemos deixar de apontar que em dado momento, sem que houvesse uma ruptura com suas pesquisas anteriores, Sartre se empenha em uma tentativa de estabelecer, na práxis, uma síntese entre o singular e o universal. Dando continuidade às suas pesquisas, o filósofo se defronta com a problemática estabelecida entre o indivíduo singular e as demais consciências também livres que, em um processo de intermitente totalização, se constituem como formadoras do quadro social e político no qual este indivíduo, com sua subjetividade, está inserido.

Sartre observa que a relação de um indivíduo com as demais consciências, na medida em que partem sempre de uma negatividade - o outro é sempre aquele que não sou eu -, vai inevitavelmente desembocar numa relação de conflito. Assim, numa "situação”, com a qual um homem se compromete, estão comprometidas, da mesma forma, inúmeras outras consciências, também ontologicamente livres e, ao mesmo tempo, imersas em um plano ôntico. Ou seja, são várias consciências presentes em suas temporalidades, carregando sua alteridade e sua negatividade. Estabelece-se aí o conflito, no interior do qual desenvolve-se a dialética das irredutibilidades e o fenômeno primário do terror como ameaça à supressão da alteridade.

A questão da liberdade surge, a partir de então, sob novas feições que se destacam num processo dialético. Ou seja, a liberdade é ela mesma o ponto de partida pelo qual o homem pode se revoltar e, através de uma práxis, lutar contra os obstáculos que o oprimem nesse campo que nada mais é do que um "Mal a ser negado". Dito de outra forma, a estrutura desse campo se apresenta como a base necessária ao surgimento de uma práxis de grupo que se organiza para negar uma negação. É, portanto, a pressão exercida por esse campo - que abriga

\footnotetext{
4 - Para-si é a denominação dada por Sartre à consciência humana.
} 
a necessidade, a escassez e a inércia - que vai possibilitar a formação de grupos como agentes modificadores de uma situação objetiva.

É diante dessa nova possibilidade de pesquisa que ele escreve a Critique de la raison dialectique e desenvolve uma investigação profunda acerca do fenômeno da escassez, estabelecendo como ponto de partida, o terreno conflitivo das relações humanas desde os seus primórdios. E sua primeira conclusão é que tais relações foram constituídas sob a forma de uma constatação ameaçadora: "não há o suficiente para todos" (SARTRE, 1985, p. 40).

A tensão da escassez se dá através do aspecto quantitativo dos indivíduos. Na medida em que as condições econômicas da luta contra a escassez exigem da sociedade uma certa organização, essa sociedade terá que definir os limites da escassez para cada um dos seus grupos, isto é, ela precisa reduzir o número de seus componentes para poder subsistir. Logo, tais grupos serão definidos por seus excedentes.

Essa redução numérica [...] não assume, de fato, a forma de homicídio, mas não há dúvida que cada sociedade escolhe discretamente seus mortos [...] não se mata, mas deixa-se morrer [...] faz-se o controle de natalidade, pois, nesse caso, cada criança ao nascer é um futuro consumidor. (SARTRE,1985, p. 240).

Com isso, a questão moral surge fundamentalmente assentada no aspecto quantitativo da humanidade e a forma histórica do maniqueísmo aparece aqui como o primeiro estágio da ética sob a forma de sociedade de classe. De fato, na medida em que a sociedade se organiza para combater a escassez, as classes se formam e, nesse caso, o Mal passa a existir no mundo sob a forma de práxis humana, como o inimigo de classe.

O sentido moral da Critique é inteiramente realista: o homem é um ser material no meio de um mundo material que o esmaga. Assim sendo, ele age pela matéria e sob a ordem da materialidade para modificar, no interior dessa dialética, esse mundo que lhe é hostil. Na verdade, a estrutura dialética da ação individual é a única base concreta da dialética histórica. A realidade histórica surge, então, sob dois aspectos aparentemente contraditórios: a atividade pela qual o sujeito faz a história, e a passividade pela qual ele é constituído. Esses dois aspectos correspondem à duas referências do processo histórico de constituição do indivíduo, ou seja: ele interioriza as determinações objetivas e exterioriza essas mesmas determinações mas já transfiguradas pela sua subjetividade. Mas a questão que nos surge imediatamente diante desse quadro conceitual é: como fica a liberdade humana, enquanto fundamento dos valores, frente à inércia dessa materialidade circundante? A liberdade, como relação humana, descobrindo-se a si mesma no mundo da exploração e da opressão, descobre-se também como 
alienada, e os valores, não encontrando mais seus limites em sua própria estrutura ontológica, serão encontrados na inércia da materialidade. Sartre conclui, então, que:

[...] todo sistema de valores repousa na exploração e na opressão, mas nega a exploração e a opressão; todo sistema de valores confirma a exploração e a opressão, mas contribui para a instalação de aparelhos que neguem a exploração e a opressão; todo sistema de valores deixa de ser sistema e os valores deixam de ser valores, porque as circunstâncias os transformam em valores superados e eles acabam sendo substituídos por novos valores descobertos. (SARTRE, 1985 p. 357).

Sem dúvida, a inteligibilidade desse processo vai depender da dialética entre as determinações históricas e a liberdade que, em seu limite, é a ação de constituir-se a si mesma e apropriar-se do mundo.

Dessa forma, o pensamento filosófico sartriano que, em suas primeiras obras, apresentava o caráter originário da liberdade, identificado com o nada de uma consciência destotalizada, na busca inalcançável da totalidade, mantém agora sua continuidade na Critique, na medida em que essa liberdade, efetivada em um processo histórico, tenta escapar da alienação que lhe vem das exigências impostas pela escassez do mundo material inerte. Com isso, podemos concluir que a eliminação da escassez é a condição de possibilidade para uma relação autêntica entre os homens. A moral torna-se, portanto, o sentido mesmo da História como uma história de emancipação, e a ética toma, assim, a forma e o sentido de uma teleologia da humanidade.

\section{Considerações finais}

Em primeiro lugar, creio ser importante reafirmar a habilidade com que Sartre passou da ontologia fenomenológica pela qual ele investigou a subjetividade humana, para uma fenomenologia do ser social para investigar um fenômeno que hoje desponta como uma enorme preocupação em nosso corpo social, a saber, a escassez.

É também interessante apontar que ele não trata da escassez como um fato, mas como um fenômeno, logo como algo que se manifesta e que é apreendido por cada um de nós como um noema, e que, assim sendo, é apreendido com as mais diversas significações.

Sartre fez uma análise do movimento histórico desenvolvido em torno desse fenômeno até meados do século XX e observou que em nossa sociedade capitalista ele sofre seu momento mais violento, pois é dentro deste quadro que surge o que ele denominou escassez 
objetiva mantida pela figura do homem-lucro: uma escassez assegurada por um sistema que só se sustenta pelo fortalecimento dessa figura. Sartre esclarece essa relação entre o lucro e a violência pelos seguintes paradoxos:

[...] se entrava o progresso em direção à abundância (achados de petróleo para vendê-lo por alto preço ou não vendê-lo) porque o lucro nasce da não-suficiência de satisfação (trabalhador e salário) e da não-abundância. $\mathrm{O}$ homem do lucro (capitalistas e seus clientes em tal ou tal época) não é o homem feudal (homem da renda) mas tanto um como outro veem na abundância a impossibilidade de poder ter a satisfação sozinho se o sistema de escassez não alcançar seu objetivo (SARTRE, 1985, p. 433).

A questão se complica porque, numa escala global, o que se constata é a construção de uma ampla rede intrincada de interesses humanos empenhada em manter a escassez como um sistema que, em princípio, vem fundamentado numa não-distribuição de riquezas, e cujos limites precisam ser respeitados para que se mantenha a margem de lucro necessária à permanência da insatisfação, pois é exatamente nessa insatisfação que reside o motor gerador do movimento em direção à conquista de novos escalões cada vez mais altos no interior desse sistema.

Mas é bem aí que Sartre pretendia chegar: as questões ligadas à moral que sempre foi a sua preocupação maior. Assim, em meio a todas as contradições que sempre fundamentaram seu pensamento, ele se coloca diante desse problema, partindo da contradição de onde ele mesmo, enquanto tal, despontava em sua exigência paradoxal: a moral é, ao mesmo tempo, impossível e necessária. De fato, é dessa forma que ela se desvelou ao filósofo, e foi assim que ele tentou introduzi-la no seio da história: em primeiro lugar, ele colocou a raiz de sua construção na necessidade, ou seja, tanto a práxis enquanto conteúdo especulativo da ética, como a ética enquanto construtora de sentido da práxis têm na necessidade seu ponto de partida. Em segundo lugar, ele fundamentou sua construção na liberdade absolutamente singular, com seu olhar voltado para o universal. Sendo assim, é desse quadro conflitivo que o filósofo empreende seu gigantesco esforço na procura de sua moral concreta e sem normas preestabelecidas, partindo de si mesmo e do mundo como dois absolutos existenciais, apoiado na facticidade de um passado, referenciado por um futuro, para buscar a possibilidade de um sentido para o presente.

Trata-se, sem dúvida, de uma empresa problemática, e o nó que ata tais problemas está na exigência de concretude que ele implica, pois o absoluto encerrado no núcleo desse nó se estende como um leque sobre uma pluralidade de consciências singulares, cada uma delas 
presentes a si mesmas e presentes entre si. Sartre dialetizou o homem, fazendo de cada escolha individual o absoluto moral pelo qual cada um se faz criador de si mesmo. Sendo assim, essa moral de criador que se dá na construção incessante da realidade e que se afirma pela recusa da inércia, torna-se uma proposta viável a qualquer realidade, pois é na permanência da mudança que ela se efetiva. Dessa forma, talvez possamos reconhecer nas palavras do filósofo, o eco de nossas apreensões mais atuais:

Há alguns decênios, nosso mundo se modifica [...]. Essa agitação tão nova, mas encarniçada para comunicar através do incomunicável, não é o desejo insípido e ingênuo de um universal inerte e já realizado: é antes o que eu designaria como o movimento de universalização [...]. Não se tem em vista ainda qualquer acordo entre os animais experimentais; os nossos universais separam-nos; [...]. Mas basta que um de nós, levado pela inquietação, se afaste da Idéia, que recuse o pensamento abstrato, [...] que procure nas circunstâncias sempre singulares e datadas, unir-se com outros [...] para tornar um pouco menos injusto o reino da Injustiça e ele obrigará os outros a reinventar esse mesmo esforço tenaz [...]. Porque hoje há apenas duas maneiras de falar de si, a terceira pessoa do singular ou a primeira do plural. É necessário saber dizer 'nós' para dizer 'eu': é um fato incontestável. [...] os vampiros fizeram uma carnificina memorável, esmagaram a esperança; é necessário a cada um de nós retomar o fôlego, [...] recomeçar tudo, inventar uma esperança morta, tentar viver. (SARTRE, 1972, p. 69).

\section{Referências}

HEIDEGGER, Martin. Que é metafísica? Trad. Ernildo Stein. São Paulo: Abril Cultural. 1973. (Col. Os Pensadores).

HUSSERL Edmund. Ideias para uma fenomenologia pura e para uma filosofia fenomenológica. Trad. Márcio Suzuki. São Paulo: Ideias e Letras, 2006.

HUSSERL Edmund. Meditaciones cartesianas. Trad. Mario A. Presas. Madri: Tecnos, 1997.

RICOEUR Paul. O conflito das interpretações. Trad. M.F. Sá Correia. Porto, 1988.

SARTRE. Jean-Paul. L'être et le néant: essai d'ontologie phénomélogique. Paris: Gallimard, 2001.

SARTRE. Jean-Paul. O existencialismo é um humanismo. Trad. Virgílio Ferreira. São Paulo: Abril Cultural. 1978. (Col. Os Pensadores).

SARTRE. Jean-Paul. Critique de la raison dialetique. Paris: Gallimard. 1982

SARTRE. Jean-Paul. A transcendência do ego. Lisboa: Colibri. 1994.

SARTRE. Jean-Paul. Situações IV. Trad, Maria Eduarda Reis Colares e Eduardo Prado Coelho. Lisboa: Publicações Europa-América, 1972. 
STEGMÜLLER Wolfang. A filosofia contemporânea. Trad. Carlos Alberto Ribeiro de Moura. São Paulo: E.P.U, 1997. 